\title{
Uma análise sobre o cenário da fome no Brasil em tempos de pandemia do COVID-19
}

\section{Resumo}

Samyra Rodrigues da Cruz ${ }^{1}$

O presente artigo tem por objetivo apresentar uma breve análise sobre a situação da fome no Brasil em tempos da pandemia do Covid-19. Partimos da compreensão que a fome consiste numa expressão da questão social brasileira. Para aclarar nossa proposta de estudo, iremos resgatar o panorama do combate à fome no Brasil no período que antecedeu a pandemia do Covid-19, com ênfase de 2003 a 2019, para apresentar nossa análise sobre este cenário durante à pandemia do covid. Assim, este artigo se constitui num estudo de caráter qualitativo, com base em revisão das produções teóricas; de pesquisa documental. Concluimos que os impactos da pandemia do Covid-19 vêm acirrando a crise econômica no Brasil, promovendo aceleração no processo, já em curso, do desmonte da Segurança Alimentar e Nutricional, ocasionando, assim, aumento de pessoas em situação de fome no país.

Palavras-chave: Fome; Questão Social; Segurança Alimentar e Nutricional; Covid-19.

\section{Abstract}

This article aims to present a brief analysis of the hunger situation in Brazil at the time of the Covid-19 pandemic. We start from the understanding that hunger is an expression of the Brazilian social issue. To clarify our study proposal, we will rescue the panorama of the fight against hunger in Brazil in the period before the Covid-19 pandemic, with emphasis from 2003 to 2019, to present our analysis of this scenario during the covid pandemic. Thus, this article is a qualitative study, based on a review of theoretical productions; documentary research. We conclude that the impacts of the Covid-19 pandemic have aggravated the economic crisis in Brazil, promoting acceleration in the process, already underway, of the dismantling of Food and Nutritional Security, thus causing an increase in people in hunger in the country.

Keywords: Hunger; Social Issues; Food and Nutrition Security; Covid-19.

${ }^{1}$ Doutoranda em Serviço Social pela Universidade Federal do Rio de Janeiro (UFRJ); Mestre em Serviço Social pela Universidade do Estado do Rio de Janeiro (UERJ); Especialista em Políticas Públicas, Gestão e Serviços Sociais pela Universidade Cândido Mendes (UCAM); Graduada em Serviço Social pela Universidade Estadual do Ceará (UECE); Assistente Social do quadro efetivo da Universidade Federal do Rio de Janeiro (UFRJ). Lattes: http://lattes.cnpq.br/0328783607352729 / E-mail para contato: samyrarcruz@gmail.com. 


\section{Introdução}

O debate em torno da fome, no Brasil, nem sempre se realizou de forma pública e coletiva, muito embora já na década de 1940, Josué de Castro² alertava a sociedade brasileira sobre o silêncio intencional do poder público acerca da fome, denunciando-a como um fenômeno de ordem social e não natural. (CASTRO, 2008).

Seguindo este mesmo horizonte, o enfrentamento da fome pelo Estado brasileiro, nem sempre se deu pela perspectiva do Direito Humano à Alimentação Adequada (DHAA), sendo negligenciada, a princípio, e posteriormente tratada como problema de produção e/ou abastecimento alimentar.

Ocorre que no percurso do processo sócio-histórico brasileiro, o campo da Segurança Alimentar e Nutricional $(\mathrm{SAN})^{3}$ foi se constituindo e se consolidando, culminando nos anos 2000 com a instituição do Sistema Nacional de Segurança Alimentar e Nutricional (SISAN), como também, com um robusto arcabouço teórico sobre o tema ${ }^{4}$.

Porém, apesar dos avanços no cenário da SAN brasileira a partir de 2003, a com promulgação das legislações específicas e criação das instâncias afetas à SAN, observamos que em tempos de crises econômicas e políticas, como a em voga no Brasil, que se agudizou por conta dos efeitos da pandemia do Covid-19, a violação do DHAA torna-se latente, afligindo principalmente segmentos específicos da população brasileira.

Portanto, este artigo tem por objetivo tecer uma breve análise sobre a situação da fome no Brasil em tempos da pandemia do Covid-19, como também, apresentar as ações

2 Josué de Castro nasceu em Recife, em 1908, e formou-se em Medicina pela Faculdade Nacional de Medicina da Universidade do Brasil. Pioneiro sobre os estudos acerca da fome no Brasil recebeu o prêmio Internacional da Paz em 1954; e foi nomeado embaixador do Brasil na ONU, em Genebra de 1962 a 1964. 3 Segundo a LOSAN, a SAN consiste "na realização do direito de todos ao acesso regular e permanente a alimentos de qualidade, em quantidade suficiente, sem comprometer o acesso a outras necessidades essenciais, tendo como base práticas alimentares promotoras de saúde que respeitem a diversidade cultural e que sejam ambiental, cultural, econômica e socialmente sustentáveis". Para mais informações ver Lei ${ }^{\circ}$ $11.346 / 2006$.

${ }^{4}$ Faz-se importante destacar que a construção do arcabouço institucional, político e normativo da Segurança Alimentar e Nutricional no Brasil ocorreu de forma tardia e enviesada, tendo a sociedade civil como protagonista no processo de mobilização em torno da discussão pública acerca da temática. Porém, devido à brevidade deste artigo, não será possível nos aprofundar nessa questão. Assim, para mais informações, ver O Direito Humano à Alimentação Adequada e o Sistema Nacional de Segurança Alimentar e Nutricional / Organizadora, Marília Leão. Brasília, 2013. 
adotadas pelo Estado brasileiro no seu enfrentamento, para tecer as perspectivas deste fenômeno social no país.

\section{Fome, Questão Social e Segurança Alimentar e Nutricional No Brasil contemporâneo.}

Embora a fome possa ocorrer por diversos motivos - catástrofes naturais, guerras e embargos políticos - neste breve estudo consideramo-la como produto da violação do direito humano à alimentação adequada, pois o não acesso ao alimento, na atual ordem societária, está relacionado com a pobreza e a desigualdade social, fenômenos inerentes à produção e reprodução das relações sociais na sociedade capitalista, conforme nos alertou Marx por meio da Lei Geral de Acumulação do Capital ${ }^{5}$.

Nesse sentido, a fome ${ }^{6}$ se reveste numa das expressões da questão social $^{7}$ na contemporaneidade brasileira, sendo, portanto, objeto por excelência tanto de pesquisa e atuação profissional do Serviço Social, como também, de intervenção do poder público, por meio das políticas sociais 8 .

Ocorre que, historicamente, o Estado brasileiro enfrentou a fome por meio de ações pontuais e fragmentadas, esvaziadas da perspectiva do direito social. Ou seja, não compreendendo ser a fome a violação de um direito básico, mas sim, um problema de abastecimento e produção (BELIK, GRAZIANO e TAKAGI, 2001) e estacionado em segundo plano, na agenda governamental por longos períodos.

No entanto, a partir dos anos 2000, com a vitória presidencial de Luís Inácio Lula da Silva em 2003, observamos a mudança na perspectiva do enfrentamento à fome no Brasil. O combate à fome passou a ser prioridade na agenda de governo, tornou-se

\footnotetext{
${ }^{5}$ Segundo a Lei Geral de Acumulação do Capital, a produção da pobreza é diretamente proporcional ao crescimento da riqueza social, que não é apropriada pela classe trabalhadora, quem a produz, mas sim, pela classe burguesa, a detentora dos meios de produção. Para mais informações ver Karl Marx em O Capital: a crítica da economia política - livro I. São Paulo. Ed. Boitempo.

6 A fome consiste numa das dimensões da INSAN. Conforme a Escala Brasileira de Insegurança Alimentar (EBIA), a INSAN pode ser considerada leve, moderada e grave.

${ }^{7}$ Compreendemos a questão social como o conjunto das expressões das desigualdades na sociedade capitalista madura. Para mais informações, ver Marilda Vilela Iamamoto em $O$ serviço social na contemporaneidade: trabalho e formação profissional. - 23. Ed. - São Paulo. Cortez. 2012.

${ }^{8}$ Neste estudo, compreendemos a política social como um processo que emerge na convergência entre os movimentos de ascensão do capitalismo, das lutas de classe e da expansão do Estado, conforme Behring e Boschetti (2009).
} 
compromisso político da referida gestão ${ }^{9}$ e ganhou status de política pública, com infraestrutura administrativa no interior de uma pasta ministerial.

O ponto de partida da referida mudança paradigmática no enfrentamento da fome consistiu na implantação do Programa Fome Zero $(\mathrm{PFZ}){ }^{10}$ que tinha como proposta a elaboração de uma política nacional de Segurança Alimentar e Nutricional. A inovação deste programa consistiu na articulação das políticas estruturais (transferência de renda, reforma agrária, emprego, dentre outras); emergenciais (as de combate à fome e a miséria) e locais (ações locais de combate à pobreza que obtiveram êxito), para combater a fome e a pobreza.

Dentro deste programa complexo e ousado, destacamos o papel do Programa Bolsa Família (PBF) no combate à fome, uma vez que ele articula a transferência de renda para famílias em situação de vulnerabilidade social sob a realização de condicionalidades vinculadas às esferas da saúde e educação. Nesse sentido, as famílias tinham acesso à renda para aquisição de alimentos, devendo cumprir as condicionalidades para permanência no programa.

Relacionado às políticas emergenciais, destacamos a estrutura normativa e jurídica da SAN, que foi sendo constituída, mesmo que tardiamente, conforme a seguinte cronologia: Criação do Ministério Extraordinário de Segurança Alimentar e Combate à Fome (MESA), em 2003; Lei Orgânica de Segurança Alimentar e Nutricional - LOSAN, em 2006, que criou o SISAN; a regulamentação e o retorno ${ }^{11}$ do Conselho Nacional de Segurança Alimentar e Nutricional (CONSEA) e da Câmara Interministerial de Segurança Alimentar e Nutricional (CAISAN), ambas em 2007; inserção do direito à alimentação na Constituição Federal, em 2010; regulamentação da Política Nacional de SAN, em 2010; e instituição do Plano Nacional de SAN em $2011^{12}$.

\footnotetext{
${ }^{9}$ É importante destacar que mesmo sendo a fome um fenômeno social que nos aflige desde os primórdios da nossa formação sócio histórica, apenas nos anos 2000 houve intenção política para estruturar políticas públicas de combate à fome, sob a responsabilidade do Estado.

${ }_{10}$ O Programa Fome Zero foi elaborado pelo Instituto Cidadania em 2001, sob a coordenação geral de José Graziano da Silva, e com a participação da sociedade civil organizada.

11 O CONSEA foi criado em 1993, no governo Itamar Franco e foi extinto em 1994, no mandato de Fernando Henrique Cardoso, sendo substituído pelo programa Comunidade Solidária. Tal ensejo simboliza o descompromisso do Estado no combate à fome, uma vez que o CONSEA é instância essencial nesta luta. 12 Importante ressaltar, também, o retorno das Conferências de SAN, espaço importante de participação social para construção desta Política Pública. No entanto, após extinção do CONSEA em 2019, as conferências deixaram de acontecer.
} 
Assim, conforme já pontuado, até meados da década de 1990, o combate à fome se deu de maneira precária, por ações pontuais e desarticuladas, com forte apelo à sociedade civil que protagonizou campanhas filantrópicas ${ }^{13}$ para atender aos famélicos do país. De acordo com o Censo Demográfico ${ }^{14}$ de 2000 , na década de $1990,35 \%$ da população (torno de 57 milhões de pessoas) se encontravam com rendimento per capita abaixo da linha da pobreza, enquanto 12,9\% (média de 21 milhões de pessoas) estavam em pobreza extrema (ALBUQUERQUE E VELOSO, 2004).

Porém, após a implantação do PFZ, observamos que os dados referentes à situação da fome no Brasil foram melhorando significativamente (PFZ, 2001). No entanto, ressaltamos que a fome jamais foi erradicada no Brasil, uma vez que sendo este fenômeno uma expressão da questão social, que é inerente à sociedade capitalista, somente com a superação desta ordem socioeconômica é que será possível sua erradicação.

Contundo, faz-se necessário esclarecer que, mesmo ciente da natureza estrutural da fome, e da raiz polarizada das políticas sociais pois correspondem, simultaneamente, tanto a um mecanismo de manutenção e reprodução da classe trabalhadora, como conquista das lutas da classe trabalhadora, consideramos as políticas sociais como importantes espaços de atuação profissional na viabilização dos direitos sociais e recuo do capital, constituindo um instrumento de promoção de justiça social, mesmo com suas limitações institucionais. (BEHRING e BOSCHETTI, 2009).

Nesse sentido, segundo a Pesquisa Nacional de Amostras por Domicílio (PNAD) 2013 ${ }^{15}$, que desenvolveu uma comparação entre os estados de INSAN nos domicílios durante os anos de 2004, 2009, e 2013, foi possível perceber as mudanças no perfil desta realidade em cada região do território brasileiro. Conforme a referida pesquisa, a INSAN nos domicílios brasileiros diminuiu entre 2009 a 2013, com 30,2\% e 22\% respectivamente.

${ }^{13}$ É oportuno mencionar a importância da sociedade civil na luta nacional pelo combate à fome, seja por meio de campanhas ou prestando visibilidade social à discussão em torno deste tema. Destacamos o sociólogo Herbert de Souza, o Betinho, mentor e organizador do projeto "Ação da Cidadania Contra a Fome, a Miséria, e pela Vida" que descortinou esse fenômeno social, a fome, como uma questão a ser enfrentada por toda a sociedade, atribuindo ao debate um caráter público, coletivo e essencial.

${ }^{14} \mathrm{O}$ Censo demográfico é uma pesquisa realizada pelo Instituto Brasileiro de Geografia e estatística (IBGE) a cada 10 anos. Através deste estudo, são reunidas informações sobre a população brasileira. Para mais informações, acessar http://www.ibge.gov.br

${ }_{15}$ O Instituto Brasileiro de Geografia e Estatística - IBGE, realizou por meio da Pesquisa Nacional por Amostragem de Domićlíos - PNAD, uma pesquisa suplementar de Segurança Alimentar e Nutricional, fazendo um balanço entre 2004, 2009 e 2013 em convênio com o Ministério do Desenvolvimento Social e combate à fome - MDS. Para mais informações, consultar o site do IBGE. 
Ressaltou que em 2013, a INSAN grave atingiu 7,2 milhões de pessoas, logo, 4,1 milhões a menos do que em 2009.

Segundo o relatório "O estado da Segurança Alimentar e Nutricional no Brasil: um retrato multidimensional, 2014", de 2001 a 2012, a renda dos 20\% mais pobres da população cresceu três vezes mais do que a renda dos 20\% mais ricos. Ou seja, de 1990 a 2012, a parcela da população em extrema pobreza reduziu de 25,5\% para 3,5\%.

Assim, conforme o último Mapa da Fome da ONU16 publicado em 2014, o Brasil diminuiu bruscamente o percentual de pessoas em situação de fome, alcançando quantitativo inferior a 5\% da população com baixo consumo calórico. Pela primeira vez na história do Brasil, saímos do grupo de países considerados em grave situação de fome e extrema pobreza, para o conjunto das nações que mais investiram em ações de Segurança Alimentar e Nutricional, o que simbolizou o esforço do Estado brasileiro no compromisso de combater à fome.

Confirmando tal assertiva, o "Relatório Nacional de Acompanhamento" (2014) emitido Instituto de Pesquisas Econômicas Aplicadas (IPEA), pontuou que Brasil foi um dos países que mais somou esforços para alcançar a meta 1 dos Objetivos do Milênio ${ }^{17}$ $(\mathrm{ODM})$ que consiste na erradicação da extrema pobreza e da fome. O documento apontou que a continuidade do Programa Fome Zero, por meio do Plano Brasil Sem Miséria $(B S M)^{18}$, no governo Dilma Rousseff ${ }^{19}$, foi condição essencial nesta conquista.

Porém, após a saída do Brasil do Mapa da Fome, um estudo realizado por um grupo constituído por mais de 40 entidades da sociedade civil, conhecido por "Grupo de Trabalho da Sociedade Civil para Agenda 2030"20, apontou que a fome voltou a ser parte da realidade brasileira, de forma latente, como nos anos de 1990.

${ }^{16}$ O Mapa da Fome é um documento elaborado periodicamente pela FAO que visa dimensionar a situação da fome no mundo, apresentando os países que avançaram, como também, os que retrocederam. Para mais informações acesse www.nacoesunidas.org.br

${ }^{17}$ Os Objetivos do Milênio (ODM) são metas estabelecidas pela Organização das Nações Unidas, em 2000, com apoio de 191 países envolvidos, dentre eles, o Brasil. Foram oito metas estabelecidas, entre estas, o ODM 1 que consiste em acabar com a fome e a miséria. Para mais informações acesse: http://www.odmbrasil.gov.br/os-objetivos-de-desenvolvimento-do-milenio

${ }^{18}$ O Programa Fome Zero teve continuidade de suas ações por meio do Plano Brasil Sem Miséria, durante a gestão de Dilma Rousseff.

${ }^{19}$ Dilma Rousseff (PT) foi a primeira mulher eleita presidente no Brasil, ganhando duas vezes as eleições presidências, em 2010 e 2014. No entanto, após golpe parlamentar, foi deposta do poder em 2016, sendo substituída pelo vice-presidente Michel Temer (MDB).

${ }^{20}$ O Grupo de Trabalho da Sociedade Civil para Agenda 2030 é um grupo composto por entidades da sociedade civil com o objetivo de monitorar o cumprimento do plano de ação voltado para o 
Conforme já dito, embora a fome não tenha sido erradicada totalmente, em determinado momento da história brasileira ela diminuiu significativamente, e este documento sinalizou que estávamos com grande possibilidade de retornarmos ao Mapa da Fome, o que simboliza forte retrocesso social ${ }^{21}$.

Desta forma, em junho de 2017, a “Agenda 2030” publicou o relatório síntese que indicou o crescente aumento da pobreza no país e, consequentemente, o retorno expressivo da fome aos lares brasileiros. Segundo o documento, as causas deste retrocesso seriam tanto a recessão e a crise fiscal, que se instalou em 2015, como também, as medidas governamentais adotadas para a saída da crise, que incidiram indiretamente na SAN como, por exemplo: a reforma trabalhista, que gerou desemprego e precarização no mundo do trabalho; reforma tributária; reforma na previdência, já iniciada no governo Lula; a Emenda Constitucional de congelamento dos gastos, que a médio e longo prazo, irá trazer consequências imensuráveis; dentre outros. Ainda conforme o documento:

Até 2014, o Brasil foi exitoso ao atingir antecipadamente o Objetivo do Desenvolvimento do Milênio de reduzir a fome e a pobreza. Nos últimos anos, porém, o cenário começou a mudar, com o enfrentamento equivocado do déficit fiscal acumulado e o descaso com problemas estruturais como a reforma tributária, levando o país a uma crise econômica e agravando o desemprego. No início de 2017, batemos o recorde da série histórica, com 14,2 milhões de trabalhadores desempregados. (AGENDA 2030, 2017, p. 8).

O site Valor Econômico ${ }^{22}$, do grupo Globo, publicou em abril de 2018 a matéria na qual dizia que a pobreza extrema havia aumentado $11 \%$ no Brasil. De acordo com a reportagem, em 2016 tínhamos 13,34 milhões de pessoas em extrema pobreza, aumentando para 14,8 milhões em 2017. Acrescentou que em todas as regiões do país os indicadores de

desenvolvimento sustentável, “Agenda 2030", acordado entre os Estados - Membros da ONU. Até 2018, o Brasil era atuante, firmando tal compromisso global para o desenvolvimento sustentável. Porém, no início do governo Bolsonaro, o Brasil vetou a participação na Agenda 2030, desfazendo a comissão governamental para este fim. Para mais informações, ver o decreto no 9759/2019.

21 Apesar de ter ocorrido fortes avanços no enfrentamento da fome no Brasil durante a transição da década de 1990 para 2000, é importante destacar novamente que a fome é um problema de amplitude estrutural e que na reprodução das relações sociais capitalistas ela jamais se esgotará, pois, sua erradicação exige profundas transformações de ordem estrutural, que vão além de intervenções institucionais por meio das políticas sociais.

${ }^{22}$ Para leitura completa da matéria, acesse o site: http://www.valor.com.br/brasil/5446455/pobrezaextrema-aumenta-11-e-atinge-148-milhoes-de-pessoas. 
pobreza pioraram, inclusive na região mais rica do país, o Sudeste, que apresentou o aumento da miséria, especialmente, Rio de Janeiro e São Paulo.

Em novembro de 2018, a ONU publicou o relatório "Panorama da Segurança Alimentar e Nutricional na América Latina e Caribe" o qual apontou que a estimativa de brasileiros que sofriam com a escassez de alimentos chegava a 5 milhões, mesmo número em 2010. De acordo com o documento, o Brasil estava fazendo caminho inverso ao esperado, pois além de estagnar na redução da fome, o quantitativo de famintos voltou a crescer.

No entanto, mesmo diante do cenário fragilizado em que se encontrava a Segurança Alimentar e Nutricional, após 2015, bem como os alertas para o possível retorno do país ao Mapa da Fome, em janeiro de 2019, o presidente Jair Bolsonaro, ainda recémempossado, publicou a Medida Provisória no 870 e extinguiu o CONSEA, o que representou um forte retrocesso da SAN brasileira. O governo Bolsonaro também vetou do Plano Plurianual (PPA) 2020 - 2023 o compromisso orçamentário com os Objetivos de Desenvolvimento Sustentáveis (ODS) e por meio do Decreto no 9759/19 desfez a comissão nacional responsável pela implementação da Agenda 2030 no Brasil.

Gradativamente, as instâncias administrativas do governo referentes à SAN foram sendo desmontadas, realocando as funções e atividades do combate à fome para outras políticas sociais. Além destas medidas é importante destacar a postura negacionista do atual presidente, e sua equipe ministerial, com relação à fome no Brasil.

Embora tanto a mídia nacional quanto as instâncias de monitoramento da SAN no país estivessem alertando às autoridades e à sociedade civil sobre o retorno da extrema pobreza, e com ela, da fome, a ministra da agricultura, pecuária e abastecimento, Tereza Cristina, afirmou em abril de 2019, que no Brasil não se passa fome por conta do quantitativo de mangueiras. Em sintonia, o presidente Bolsonaro ${ }^{23}$, afirmou em julho do mesmo ano, que não existem pessoas em situação de fome no Brasil, sendo mentira tal afirmação.

Nesse sentido, é possível observar, claramente, o retorno do silêncio intencional do Estado diante da fome no Brasil, uma vez que o atual governo afirma desconhecê-la em

23 Para mais informações acesse: https://oglobo.globo.com/brasil/passar-fome-no-brasil-uma-grandementira-diz-bolsonaro-23818496. Acessado em: 20/07/2020 
território brasileiro, mesmo que as instâncias de monitoramento apontem o seu crescimento. E, ao não reconhecer a volta da fome, de maneira exponencial, o Estado brasileiro tanto viola quanto negligencia o direito humano à alimentação da população mais pobre, fomentando o caminho de retorno do Brasil ao grupo dos países em situação de extrema pobreza e fome.

\section{A Situação Da Fome No Brasil Durante a Pandemia Do Covid-19 e suas perspectivas.}

Durante a passagem do ano de 2019 para o de 2020, o mundo foi surpreendido com a transmissão do novo coronavírus ${ }^{24}$, o SARS - COV - 2, provocando a Covid-1925, uma doença até então desconhecida, com forte poder de transmissibilidade e altas taxas de letalidade que vem desafiando os cientistas do mundo inteiro, tanto para compreendê-la, como para buscar uma vacina capaz de imunizar a população ${ }^{26}$.

Deste modo, a Organização Mundial da Saúde (OMS) iniciou forte mobilização para que os países adotassem as medidas preconizadas pelos cientistas (distanciamento e/ou isolamento social, uso de máscaras e higienização constantes das mãos), com o objetivo de retardar a curva de crescimento dos mortos e infectados até descobrirem um tratamento mais eficiente e/ou uma possível cura para a doença.

Porém, alguns líderes mundiais ignoraram as recomendações da OMS e assumiram uma postura negacionista da ciência. No Brasil, essa conduta conservadora foi adotada pelo Chefe do Executivo e tomou grandes proporções, pois influenciou de forma negativa uma parcela da população a não seguir as orientações científicas e minimizou os possíveis impactos da doença.

${ }^{24}$ Os coronavírus são uma grande família de vírus comuns em muitas espécies diferentes de animais, incluindo camelos, gado, gatos e morcegos. Para mais informações, acesse https://coronavirus.saude.gov.br/sobre-a-doenca\#o-que-e-covid . Acessado em: 10/08/2020.

25 A COVID-19 é uma doença causada pelo coronavírus, denominado SARS-CoV-2, que apresenta um espectro clínico variando de infecções assintomáticas a quadros graves. De acordo com a Organização Mundial de Saúde, a maioria (cerca de 80\%) dos pacientes com COVID-19 podem ser assintomáticos ou oligossintomáticos (poucos sintomas), e aproximadamente $20 \%$ dos casos detectados requer atendimento hospitalar por apresentarem dificuldade respiratória, dos quais aproximadamente $5 \%$ podem necessitar de suporte ventilatório.

26 Até a primeira quinzena do mês de agosto de 2020, o Brasil alcançou 3.340 .197 casos confirmados e 107.852 óbitos pelo novo coronavírus. Para mais informações, acesse: https://covid.saude.gov.br/ 
Nesse sentido, foi necessária a intervenção do Supremo Tribunal Federal (STF), que concedeu autonomia aos estados e municípios para tomada de decisões no combate da nova pandemia do coronavírus, pois, conforme dito, o Governo Federal negligenciou suas responsabilidades na condução de um planejamento nacional; teceu diretrizes conflituosas à população e aos profissionais da equipe técnica do governo, gerando conflitos e desgastes, culminando na exoneração de dois ministros da saúde, em plena pandemia, e permanecendo até o momento com um ministro sem formação na área médica.

Desta maneira, vários são os impactos ocasionados pela nova pandemia do coronavírus, acirrando a crise econômica e política já existente no país, pois, a covid-19 nos forçou a uma nova sociabilidade, pautada pelo afastamento e/ou isolamento social devido à sua alta transmissibilidade, o que afetou todas as atividades humanas presenciais e descortinou as desigualdades sociais e econômicas já presentes no país. Porém, estamos convencidos de que a má gestão da pandemia, ou ausência dela, por parte da União vem agravando o cenário brasileiro. E, dentre estas questões, destacamos da fome.

Vejamos a fala do ex-diretor da FAO, José Graziano, em entrevista para o jornal Brasil de Fato:

[...] o governo Bolsonaro tem sido mais explícito no desmonte da política de segurança alimentar construída no primeiro governo Lula e que foi responsável pela saída do Brasil do Mapa da Fome. Nessa circunstância de desmonte da política de segurança alimentar e nutricional no Brasil não há dúvida de que nós corremos o risco de voltar ao Mapa da Fome ainda em 2020 com os efeitos dessa pandemia. (BRASIL DE FATO, 2020) (grifo nosso).

Segundo os dados levantados pelo relatório da FAO "Estado da Segurança Alimentar e Nutrição no Mundo 2020” o Brasil ainda não retornou, teoricamente, ao Mapa da Fome, permanecendo com menos de 5\% de pessoas em situação de restrição alimenta severa. No entanto, tal adiamento se deu, de acordo com Daniel Balaban, em entrevista exclusiva ao jornal "Brasil de Fato"27, porque tanto não foram considerados os efeitos socioeconômicos da crise do novo coronavírus no referido documento, como também,

27 Daniel Balaban é direto do "Centro de Excelência Contra a Fome do Programa Mundial de Alimentos" da ONU. Para acessar na íntegra a entrevista, ver https://www.brasildefato.com.br/2020/07/14/se-nadafor-feito-voltamos-ao-mapa-da-fome-diz-diretor-da-onu-sobre-brasil. Acessado em 14/08/2020. 
novos elementos foram apreciados nesta pesquisa, a exemplo, a alimentação escolar prestada em 2019, que teve reflexos positivos no documento apresentado em 2020.

No entanto, segundo a referida reportagem, ao considerar o processo já em curso de desmonte das políticas de SAN, iniciado no governo Temer e potencializado na gestão Bolsonaro, e somando os desdobramentos da pandemia do Covid-19, possivelmente retornaremos ao Mapa da Fome da ONU, em breve. Vejamos:

$\mathrm{Na}$ avaliação de Balaban, caso as políticas sociais continuem sendo deixadas de lado e as políticas voltadas para a agricultura familiar, responsável pela produção de $70 \%$ da alimentação no país, não sejam retomadas a todo vapor, a perspectiva é negativa. "Se nada for feito, não existe milagre. Vamos ao caminho de volta ao Mapa da Fome”. (BRASIL DE FATO 2020).

Segundo o relatório "Como evitar que a crise da covid-19 se transforme em uma crise alimentar: Ações urgentes contra a fome na América Latina e no Caribe" elaborado pela Comissão Econômica para a América Latina e o Caribe (Cepal) e pela FAO, a fome já é uma das consequências imediatas da pandemia, e se tornará um grande desafio, a médio e longo prazo a ser enfrentado pelos governos mundiais. De acordo com o documento, estima-se que em relação a 2019, em 2020 a quantidade de pessoas em extrema pobreza alcançará 16 milhões a mais, chegando a 83 milhões de pessoas, um número estratosférico.

Assim, conforme José Graziano, o aumento da situação de pessoas com fome no Brasil será inevitável e ocasionará desdobramentos imensuráveis. Vejamos:

Hoje eu vejo com muita tristeza que o Brasil está no caminho de voltar ao
Mapa da Fome por exatamente deixar de cumprir os elementos principais
de uma política de segurança alimentar. O governo Bolsonaro tem
continuado o desmonte, de forma mais explícita, iniciado no governo
Temer, de não priorizar as políticas de segurança alimentar, isso inclui a
extinção do Conselho Nacional de Segurança Alimentar e Nutricional
(Consea), isso inclui a redução dos recursos para compras da agricultura
familiar, inclui também a redução da política de alimentação escolar que
vinha se ampliando nos últimos anos.(BRASIL DE FATO, 2020).

De acordo com os dados da PNAD Covid ${ }^{28}$, publicada em setembro de 2020, o número de pessoas desempregadas atingiu 13,5 milhões de pessoas, sendo 3,4 milhões a mais que no mês de maio, representando aumento de $33,1 \%$. E considerando as projeções feitas pelo instituto, estima-

${ }^{28}$ A PNAD Covid consiste num levantamento realizado pelo IBGE em parceira com Ministério da Saúde para identificar os efeitos da pandemia no mercado de trabalho no Brasil e quantificar o número de pessoas com sintomas da síndrome gripal. Porém, os dados da Pnad Covid não são comparáveis aos dados da Pnad contínua, que mede o desemprego no país. Para mais informações acesse: www.ibge.gov.br 
se que este cenário se agravará devido à inexistência de uma vacina capaz de imunizar a população e permitir o retorno ao mercado. Ainda neste horizonte, o Fundo das Nações Unidas para Infância (UNICEF) alertou que 30\% das famílias mais pobres do Brasil passaram fome nos últimos dois meses de $2020^{29}$.

Assim, com objetivo de amenizar economicamente os efeitos da pandemia, o governo brasileiro foi impelido pela oposição a criar uma renda básica, no valor de $\mathrm{R} \$ 600^{30}$, para a população mais afetada pela crise econômica em curso. O “Auxílio Emergencial” conta com pagamento de três parcelas no referido valor, por meio da Caixa Econômica Federal e segue critérios de renda para sua concessão. No entanto, o benefício acabou sendo reduzido para $R \$$ 300,00, nos seus últimos pagamentos (três últimas parcelas) e adotou critérios mais restrito na sua concessão.

Assim, além da incerteza quanto à sua continuidade, mesmo sem o fim da pandemia no mundo, o que poderá agravar, ainda mais, a situação brasileira, alguns segmentos da população ficaram descobertos pelo benefício, como também, quem teve acesso relatou dificuldades em receber o dinheiro.

Mas, para além da questão econômica, fazemos um breve destaque para a dimensão social e cultural em torno da fome. Observamos constantemente a divulgação sobre os dados da fome na mídia nacional, porém não há uma discussão governamental em torno da questão. O que estamos acompanhando é o retorno do protagonismo da sociedade civil organizada, que vem se mobilizando por meio de campanhas de cunho filantrópico para amenizar as dores da fome no país.

\section{Conclusão}

Apesar de a fome ser um fenômeno que assola a sociedade brasileira desde o início da sua formação sócio histórica, nem sempre o Estado a compreendeu como uma violação do direito básico, relacionando-a à pobreza e à desigualdade social. Assim, o seu enfrentamento se deu, historicamente, por meio de ações pontuais e fragmentadas, o que

29 Para mais informações ver https://agenciabrasil.ebc.com.br/radioagencia-nacional/geral/audio/202012/unicef-13-das-familias-brasileiras-deixaram-de-comer-na-pandemia

${ }^{30} \mathrm{O}$ auxílio emergencial é um benefício instituído no Brasil pela Lei de $\mathrm{n}^{\circ}$ 13.982/2020 que prevê o repasse de 600 reais mensais (inicialmente por três meses) a trabalhadores informais e de baixa renda, microempreendedores individuais e também contribuintes individuais do Instituto Nacional do Seguro Social (INSS). Para mais informações acesse: https://auxilio.caixa.gov.br/\#/inicio 
nos levou a níveis recordes de pessoas em situação de fome em um país com grande potencial agropecuário e forte produção de alimentos para exportação.

Desta maneira, quando partimos da compreensão que a fome consiste numa expressão da questão social na contemporaneidade, faz-se necessário esclarecer que erradicação deste fenômeno, na sua totalidade, torna-se uma meta de inatingível, uma vez que as relações sociais desiguais são inerentes ao sistema capitalista, acentuando-se em países periféricos e dependentes como o Brasil. Assim, as políticas sociais cumprem o papel de viabilização dos direitos sociais, criando a possibilidade na promoção da justiça social, no entanto, não são capazes de erradicar a fome.

Neste horizonte, quando compreendermos que as políticas sociais são perpassadas por interesses econômicos, políticos e sociais, é possível entender que estas avançam e retrocedem à medida que se expande ou se retraia a acumulação do capital, haja vista seu caráter histórico. Destarte, em posse deste pressuposto, é possível observar que em períodos de crise no sistema capitalista, como a em voga no Brasil e no mundo, as políticas sociais se tornam objetos de fácil ataque por parte do Estado, especialmente, as políticas sociais voltadas para a pobreza e a fome.

Deste modo, conforme já mencionado, após o período de consolidação e estruturação das Políticas de Segurança Alimentar e Nutricional no Brasil, iniciado em 2003 com o governo Lula, iniciou-se o processo de desmonte da SAN em 2016, no governo Temer, acentuando-se na gestão Bolsonaro, causando grandes retrocessos sociais.

Somando-se à conjuntura retrógrada no combate à fome no Brasil, fomos apanhados pela pandemia do novo coronavírus, o que agravou o quadro já em curso, haja vista a ausência do Governo Federal na gestão política e técnica da pandemia, desamparado os entes federativos e os impelindo ao protagonismo no exercício do combate à covid-19 e seus desdobramentos estratosféricos.

Nesse sentido, com a "orfandade" federal e o comprometimento no desenvolvimento das atividades humanas devido ao afastamento social, o que observamos é o impacto nas condições de vida da população, vulnerabilizando os segmentos mais pobres, e agudizando a situação de fome no Brasil.

No entanto, além da concessão de renda básica, faz-se necessária a adoção de medidas mais urgentes no combate à extrema pobreza, conforme indicado no relatório da CEPAL e da FAO, como por exemplo, as políticas de segurança alimentar e nutricional. 
Por exemplo, devido ao isolamento social, vários estados e municípios restringiram as aulas presenciais, transferindo-as para o ambiente virtual, o que impossibilitou para muitas crianças e adolescentes a realização da refeição mais nutritiva do dia, ou até mesmo, a única consumida.

Assim, conforme o relatório, faz-se urgente o reforço nos programas de alimentação escolar. Mas, é necessário, também, o apoio às iniciativas de assistência alimentar da sociedade civil; crédito e subsídios produtivos à agricultura familiar, buscando dinamizar a produção e distribuição de alimentos no país, fomentando o acesso de todos à alimentação adequada, e combatendo a alta nos preços dos alimentos.

Assim, diante do projeto em curso de neglicenciamento da fome no Brasil, estamos convencidos que o cenário da fome no país se acentuará, arrastando milhares de pessoas à situação da extrema pobreza. No entanto, como estamos analisando um processo ainda em curso e compreendemos que a realidade é dinâmica e complexa, não podemos, e nem temos a presunção, de esgotar esta discussão, o que nos leva a constante reflexão e estudo. Mas apostamos na correlação de forças entre sociedade civil e Estado, em torno desta da questão da fome, como possibilidade de mudança nos rumos do país.

\section{Referências}

ALBUQUERQUE, Roberto Cavalcanti de. VELlOSO, João Paulo dos Reis. (coordenadores). A nova geografia da fome e da pobreza. - Rio de Janeiro: José Olympio, 2004

BEHRING, Elaine. BOSCHETTI, Ivanete. Política Social: fundamentos e história. - 6 ed.- São Paulo: Cortez, 2009.

BELIK, Walter. SILVA, José Graziano da. TAKAGI, Maya. Políticas de combate à fome no Brasil. In: São Paulo em Perspectiva, 15(4) 2001.

BRASIL, Lei no 11.346, de 15.09.2003. Lei Orgânica de Segurança Alimentar e Nutricional- LOSAN. Diário Oficial da
República Federativa do Brasil. Brasília, 2003.

BRASÍLIA. O estado da Segurança Alimentar e Nutricional no Brasil: um retrato multinacional. Relatório 2014. Brasília, DF. 2014

CASTRO, Josué de. Geografia da Fome $9^{a}$ edição. - Rio de Janeiro: Civilização Brasileira, 2008.

GRUPO DE TRABALHO DA SOCIEDADE CIVIL PARA AGENDA 2030. Relatório Luz da Agenda 2030 de desenvolvimento sustentável: síntese. (Brasil). [S.l.: s.n.], 2017. 
IAMAMOTO, Marilda Vilela. O serviço social na contemporaneidade: trabalho e formação profissional. - 23. Ed. - São Paulo. Cortez. 2012.

INSTITUTO BRASILEIRO DE GEOGRAFIA E ESTATÍSTICA (IBGE). Pesquisa nacional de amostras por domicílios 2009: suplemento segurança alimentar. Rio de Janeiro, 2010c.

Pesquisa nacional de amostras por domicílios 2013: suplemento segurança alimentar. Rio de Janeiro, 2014.

Síntese de indicadores sociais: uma análise das condições de vida da população brasileira: 2016 / IBGE, Coordenação de População e Indicadores Sociais. - Rio de Janeiro: IBGE, 2016.

INSTITUTO DE PESQUISA E ESTUDOS APLICADOS (IPEA). Objetivos de Desenvolvimento do Milênio. Relatório nacional de acompanhamento. IPEA, Brasília, DF, 2014.

(IPEA). Sobre a evolução recente da pobreza e da desigualdade. Brasília, DF, 2009.

MARX, KARL. O Capital: crítica da economia política: livro I. Ed. Boitempo. São Paulo, 2013.

Organização das Nações Unidas (ONU) e Comissão Econômica para a América Latina e o Caribe (CEPAL). Como evitar que a crise da covid-19 se transforme em uma crise alimentar: Ações urgentes contra a fome na América Latina e no Caribe. Roma, 2020.
Organização das Nações Unidas (ONU). Panorama da Segurança Alimentar e Nutricional na América e no Caribe. Nova Iorque, 2018. - Estado da Segurança Alimentar e Nutrição no Mundo 2020. Roma, 2020. 